\title{
Formulation Development and Evaluation of Poorly Water Soluble Gliclazide Tablet Containing Aerosil 380 as Carrier
}

\author{
Mir Rashed Ali, Kaniz Fatema Asha, Subrata Paul, Bytul M. Rahman* \\ Department of Pharmacy, Faculty of Science, Rajshahi University, Rajshahi, Bangladesh \\ Email: ^bmokaddes@yahoo.com
}

How to cite this paper: Ali, M.R., Asha, K.F., Paul, S. and Rahman, B.M. (2019) Formulation Development and Evaluation of Poorly Water Soluble Gliclazide Tablet Containing Aerosil 380 as Carrier. Pharmacology \& Pharmacy, 10, 396-405.

https://doi.org/10.4236/pp.2019.109032

Received: August 1, 2019

Accepted: September 8, 2019

Published: September 11, 2019

Copyright (c) 2019 by author(s) and Scientific Research Publishing Inc. This work is licensed under the Creative Commons Attribution-NonCommercial International License (CC BY-NC 4.0). http://creativecommons.org/licenses/by-nc/4.0/

\begin{abstract}
The core objective of the current work was to improve dissolution rate of poorly water-soluble anti-diabetic drug gliclazide by solid dispersions (SDs) technique using fumed silica particles Aerosil 380 as carrier into compressed tablets. Different FGA-1, FGA-2, FGA-3 (Formulated Gliclazide Aerosil; weight ratio, 1:1) and FPG-1, FPG-2 (Formulated Plain Gliclazide) tablet batches were formulated, prepared, evaluated and characterized. All the findings of pre-compression factors were found to be satisfactory and post-compression parameters revealed good mechanical integrity and good uniformity in all formulations. All the formulated tablets satisfied the compendia limits of weight variation, friability and the disintegration time. Among all formulations, FGA-3 was optimized based on in vitro drug release findings, disintegration time, hardness and other quality attributes. The percent of drug release from the formulated FGA tablets containing gliclazide loaded aerosil is about 3 fold higher when compared with the tablets formulated and prepared with plain gliclazide (FPG) and the tested commercial brands in first $60 \mathrm{mi}-$ nutes. There was no significant change noted in the drug content and drug release pattern in the FGA tablets batches when stored in $40^{\circ} \mathrm{C}$ and $75 \% \mathrm{RH}$ for three months. It was thus concluded that SDs formulations of gliclazide could be successfully used to design and develop a solid dosage form of the drug, which would have significant benefits over the existing commercial brands.
\end{abstract}

\section{Keywords}

Solid Dispersions, Gliclazide, Aerosil 380, Tablet, Dissolution Profile

\section{Introduction}

More than $40 \%$ of newer drug molecules are hydrophobic nature possessing 
poor aqueous solubility, resulting in low bioavailability and reduced patient compliance having frequent administration of drug. Hence there is a need to address these concerns by developing and designing appropriate drug carrier system to enhance solubility of poorly water-soluble drugs.

Gliclazide is a second-generation hypoglycemic sulfonylurea used in the treatment of type 2 diabetes [1] [2]. As a poorly water-soluble drug gliclazide possess drawback of low aqueous solubility [3] [4] [5], it is important to enhance their solubility and that could help in diabetic treatment with reduced dose. Enhancing the dissolution rate and subsequently the bioavailability by increasing the surface area is well documented [6] [7]. In recent times, porous and mesoporous silica materials are characterized by the large specific surface area and have been reported to be a step ahead for enhancing drug solubility and oral bioavailability [8].

Solid dispersions represent a promising formulation approach to overcome today's major challenge in pharmaceutical industry of developing bioavailable solid dosage form for poorly water-soluble drugs [9] [10] through applying different methodologies including solvent evaporation methods [11].

Recently, Subrata et al. reported a remarkable improvement of dissolution rate of gliclazide in the solid dispersions loaded with Aerosil 380 (weight ratio, 1:1) when compared to the plain gliclazide in water medium and hence were pharmacologically more active than that of conventional gliclazide form [12].

The objective of the study was to identify the extragranular component requirements (level and type of excipients) to develop and optimize the gliclazide formulation for enhancing the dissolution rate of drug by formulating solid dispersions of gliclazide in Aerosil 380 into directly compressed tablets.

\section{Materials and Methods}

\subsection{Materials}

Gliclazide, Starch-1500, spray dried lactose, sodium starch glycolate, magnesium stearate and cross povidone were gift samples from Square pharmaceuticals Ltd., Pabna, Bangladesh. Silica (Aerosil 380) was taken from Evonik Pvt. Ltd., Hanau, Germany. Ethanol and methanol were purchased from Hong Yang Chemical Corporation, China and Merck, Germany, respectively. Potassium dihydrogenphosphate, sodiumhydroxide and hydrochloric acid $(35 \%$ - 38\%) were purchased from Scharlab S. L. Spain; Merck Specialities Private Ltd India; and Merck, Germany; respectively. All chemicals used in the study were of analytical grade.

\subsection{Estimation of Gliclazide}

A spectrophotometric method based on the absorbance of UV rays at $\lambda_{\max }$ of 229 $\mathrm{nm}$ was used in the study for the estimation of the amount of gliclazide present in the solid dispersions and in the tablets. An accurately weighed $25 \mathrm{mg}$ of gliclazide was dissolved in $20 \mathrm{ml}$ of methanol in a $25 \mathrm{ml}$ volumetric flask and the volume was adjusted up to $25 \mathrm{ml}$. Then appropriate aliquot portions of $0.2 \mathrm{ml}$ of 
stock solution were transferred to $50 \mathrm{ml}$ volumetric flasks and volume of flask was adjusted to $50 \mathrm{ml}$ with methanol. The solution was filtered through $0.45 \mu \mathrm{m}$ millipore filter and the absorbance of solutions was measured in an UV spectrophotometer (Shimadzu, Japan) at $\lambda_{\max } 229 \mathrm{~nm}$ against methanol as blank and calibration curve of gliclazide was constructed.

\subsection{Preparation of Solid Dispersions by Solvent Evaporation Method}

Solid dispersions (SDs) of gliclazide and Aerosil 380 (GA) were prepared in 1:1 ratios of drug: carrier by solvent evaporation method. Accurately weighed gliclazide powder was dissolved in appropriate volume of ethanol, into which same amounts of silica particle were added and dispersed in the drug solution under continuous stirring for $30 \mathrm{~h}$ by magnetic stirrer with $200 \mathrm{rpm}$ at $50^{\circ} \mathrm{C}$ to allow satisfactory loading of the drug in silica surface and to evaporate the solvent from the dispersion system. The dried solid dispersions was obtained as hardened mixture that was grinded in a mortar and pestle and passed through sieve $\# 60$ and stored in a screw-cap vial at room temperature until further use.

\subsection{Preparation of Gliclazide Tablets}

Compressed tablets each containing $80 \mathrm{mg}$ of gliclazide was prepared by direct compression method employing gliclazide alone (FPG-1, FPG-2) and its solid dispersions in Aerosil 380 (FGA-1, FGA-2, FGA-3). Quantities of the SDs, drug substance and excipients are weighted accurately as mentioned in Table 1 . The solid dispersion was mixed with the excipients and then it was blended for 5 minutes to get the uniformity of blend. From the above blend, a definite quantity that was equivalent to $80 \mathrm{mg}$ of drug substance was weighed and compressed in to a tablet by using the single punch $(8 \mathrm{~mm})$ tablet compression machine (India) to get a tablet of desired weight.

Prior to compression, powder blends were evaluated for precompression parameters like angle of repose, tapped density, bulk density, Hausner's ratio [tapped/bulk density ratio) and Carr's compressibility index [13]. To measure

Table 1. Formulation of tablets containing GA solid dispersions and plain gliclazide.

\begin{tabular}{cccccc}
\hline Formulation Code $\rightarrow$ Composition $\downarrow$ & FGA-1 & FGA-2 & FGA-3 & FPG-1 & FPG-2 \\
\hline Gliclazide-Aerosil 380 & 205 & 205 & 205 & - & - \\
Solid Dispersions (mg) & & & & & \\
Pure Gliclazide (mg) & - & - & - & 80 & 80 \\
Starch-1500 (mg) & 31.5 & 45 & - & 30 & 30 \\
Spray Dried Lactose (mg) & 52 & 31.5 & 76.5 & 178.5 & 54 \\
Na-Starch Glycolate (mg) & 10 & 10 & 10 & 10 & 10 \\
Mg-Stearate (mg) & 1.5 & 1.5 & 1.5 & 1.5 & 1.5 \\
Cross Povidone (mg) & - & 7 & 7 & - & - \\
\hline
\end{tabular}

FGA: Formulation of Gliclazide loaded Aerosil; FPG: Formulation of Plain Gliclazide. 
the angle of repose, $10 \mathrm{gm}$ of powder was poured through a glass funnel onto a flat surface and the angle to the horizontal was measured. The measurements were performed in triplicate.

\subsection{Characterization of Gliclazide Tablets}

Physical properties like weight variation, hardness and friability of the newly formulated tablets were determined according to the USP 24 methods [14]. For estimating weight variation, 20 tablets from each formulation were taken randomly and weighed. The weights of individual tablets were then compared with the average weight that was already calculated. Hardness of the tablets was measured by recording the force to fracture a tablet on a hardness tester for 6 tablets from each batch using Monsanto tablet hardness tester.

Friability was determined using friability test apparatus for 20 tablets at 25 rpm for 4 minutes. Six tablets were taken and examined from each formulation for disintegration time at $37^{\circ} \mathrm{C} \pm 2{ }^{\circ} \mathrm{C}$ in water. For determination of drug content, gliclazide tablets from a batch were taken at random and were crushed to fine powder. A powder mass equivalent to $80 \mathrm{mg}$ of gliclazide was weighed and dissolved adequately in dichloromethane and filtered. The filtrate was collected, diluted correctly and examined for the content of gliclazide by UV-Spectrophotometer at $\lambda_{\max } 229 \mathrm{~nm}$ (Shimadzu, Japan).

\subsection{In Vitro Drug Release Study}

The in vitro dissolution study was carried out according to the USP 24 specifications [14] with Apparatus $2(\mathrm{n}=3)$. The dissolution medium consisted of 900 $\mathrm{mL}$ of water maintained at $37^{\circ} \mathrm{C} \pm 0.5^{\circ} \mathrm{C}$ and stirred at $50 \mathrm{rpm}$. An aliquot of 10 $\mathrm{ml}$ was withdrawn at preset intervals, filtered through a $0.45 \mu \mathrm{m}$ membrane filter (Millipore, USA) and replaced with an equal amount of fresh dissolution medium, to maintain the constant volume of dissolution medium throughout the entire experiment. The amount of the gliclazide dissolved was analyzed by UV-Spectrophotometer at $\lambda_{\max } 229 \mathrm{~nm}$ after suitable dilution of the samples.

\subsection{Stress on Formulated Tablets}

The newly formulated tablets were closely packed in air-tight containers which were impermeable to solid, liquid and gases, then stored at $40^{\circ} \mathrm{C} \pm 2^{\circ} \mathrm{C}$ for three months. After three months of storage, the samples were collected and analyzed for hardness, disintegration time, drug content and drug release rate. Then the data was analyzed statistically to test the significant variation at 5\% level of significance. Then the similarity index (F2) was calculated between dissolution rates of tablets before and after storage to prove the stability of tablets.

\section{Results and Discussions}

\subsection{Physical Characteristics of Prepared Formulations before Compression}

All the prepared formulation of the plain gliclazide and solid dispersion blends 
(FGA-1, FGA-2, FGA-3, FPG-1 and FPG-2) were evaluated before compression for angle of repose, bulk density, tapped density, Carr's index and Hausner's ratio. The results in Table 2 reflected that all the formulations blends exhibited good flow property that is needed for tableting process.

\subsection{Evaluation of Tablets}

The SDs of GA (gliclazide with aerosol 380)and plain gliclazide (PG) was formulated into fast dissolving tablets with direct compressible excipients by the direct compression method. The quality control parameters of all the tablet formulations and marketed products are represented in Table 3. The drug content of all the tablet formulations was determined and found within the range of $99.78 \%$ to $101.62 \%$, reflecting good uniformity among different tablet formulations when compared to marketed tablets (MP-1, MP-2, MP-3, and MP-4) ranged from $96.26 \%$ to $98.96 \%$.

Table 2. Evaluation of pre-compression parameters of gliclazide tablets formulation blends.

\begin{tabular}{cccccc}
\hline $\begin{array}{c}\text { Formulation } \\
\text { Code }\end{array}$ & $\begin{array}{c}\text { Bulk density } \\
(\mathrm{gm} / \mathrm{ml})\end{array}$ & $\begin{array}{c}\text { Tapped } \\
\text { density } \\
(\mathrm{gm} / \mathrm{ml})\end{array}$ & $\begin{array}{c}\text { Angle of } \\
\text { repose }\end{array}$ & $\begin{array}{c}\text { Compressibility } \\
\text { index }(\%)\end{array}$ & $\begin{array}{c}\text { Hausner's } \\
\text { ratio }\end{array}$ \\
\hline FGA-1 & $0.41 \pm 0.01^{\star \dagger \dagger}$ & $0.46 \pm 0.02^{\dagger}$ & $33^{\circ} 69^{\prime \prime} \pm 0.5^{* \dagger \dagger}$ & $13.39 \pm 0.5^{* * * \dagger \dagger \dagger}$ & $1.15 \pm 0.25^{* \dagger \dagger}$ \\
FGA-2 & $0.38 \pm 0.02^{\dagger \dagger}$ & $0.44 \pm 0.02^{\dagger}$ & $32^{\circ} 62^{\prime \prime} \pm 0.5^{\star * \dagger \dagger}$ & $13.64 \pm 0.55^{\star * \dagger \dagger \dagger}$ & $1.16 \pm 0.03^{* \dagger}$ \\
FGA-3 & $0.38 \pm 0.02^{\dagger \dagger}$ & $0.47 \pm 0.02^{\dagger}$ & $34^{\circ} 22^{\prime \prime} \pm 0.45^{\star \dagger \dagger}$ & $19.15 \pm 0.57^{\dagger \dagger}$ & $1.24 \pm 0.02^{\dagger}$ \\
FPG-1 & $0.36 \pm 0.01$ & $0.48 \pm 0.01$ & $36^{\circ} 43^{\prime \prime} \pm 0.45$ & $20.56 \pm 0.52$ & $1.31 \pm 0.03$ \\
FPG-2 & $0.2 \pm 0.02$ & $0.29 \pm 0.03$ & $38^{\circ} 12^{\prime \prime} \pm 0.51$ & $23.67 \pm 0.52$ & $1.42 \pm 0.04$ \\
\hline
\end{tabular}

FGA: Formulation of Gliclazide loaded Aerosil; FPG: Formulation of Plain Gliclazide. Data are expressed as mean \pm SEM $(n=3) .{ }^{*} \mathrm{p}<0.05,{ }^{* *} \mathrm{p}<0.01$ and ${ }^{* * *} \mathrm{p}<0.001$ versus FPG $-1 .{ }^{\dagger} \mathrm{p}<0.05,{ }^{\dagger \dagger} \mathrm{p}<0.01$ and ${ }^{\dagger \dagger \dagger} \mathrm{p}<$ 0.001 versus FPG-2.

Table 3. Post compression physical parameters of gliclazide formulated tablets and marketed products.

\begin{tabular}{ccccccc}
\hline $\begin{array}{c}\text { Formulation } \\
\text { Code }\end{array}$ & $\begin{array}{c}\text { Target } \\
\text { Weight }\end{array}$ & $\begin{array}{c}\text { Weight } \\
\text { Variation }(\%)\end{array}$ & $\begin{array}{c}\text { Friability } \\
(\%)\end{array}$ & $\begin{array}{c}\text { Hardness } \\
\left(\mathrm{kg} / \mathrm{cm}^{2}\right)\end{array}$ & $\begin{array}{c}\text { Disintegration } \\
\text { Time }(\mathrm{sec})\end{array}$ & $\begin{array}{c}\text { Drug Content } \\
(\%)\end{array}$ \\
\hline FGA-1 & 300 & $1.23 \pm 0.02$ & $0.13 \pm 0.02$ & $3.35 \pm 0.5$ & $84 \pm 12.0^{* * *}$ & $99.9 \pm 0.60$ \\
FGA-2 & 300 & $1.17 \pm 0.05$ & $0.16 \pm 0.04$ & $3.2 \pm 0.45$ & $21 \pm 3.0^{* * *}$ & $99.87 \pm 0.51$ \\
FGA-3 & 300 & $1.01 \pm 0.05^{*}$ & $0.33 \pm 0.06^{*}$ & $3.6 \pm 0.55$ & $33 \pm 3.0^{* * *}$ & $99.94 \pm 0.50$ \\
FPG-1 & 300 & $1.77 \pm 0.05^{* *}$ & $1.64 \pm 0.07^{* * *}$ & $2.3 \pm 0.5$ & $26 \pm 1.5^{* * *}$ & $101.62 \pm 1.00$ \\
FPG-2 & 175 & $1.06 \pm 0.04^{*}$ & $1.24 \pm 0.05^{* * *}$ & $0.86 \pm 0.1^{*}$ & $77 \pm 4.0^{* * *}$ & $99.78 \pm 0.54$ \\
MP-1 & 175 & $1.3 \pm 0.04$ & $0.11 \pm 0.02$ & $2.41 \pm 0.5$ & $380 \pm 10.0$ & $98.96 \pm 0.50$ \\
MP-2 & 200 & $1.5 \pm 0.03$ & $0.38 \pm 0.05$ & $2.15 \pm 0.5$ & $33 \pm 3.0$ & $96.26 \pm 1.00$ \\
MP-3 & 200 & $0.46 \pm 0.01$ & $0.1 \pm 0.01$ & $4.2 \pm 0.5$ & $390 \pm 15.0$ & $97.7 \pm 0.50$ \\
MP-4 & 200 & $1.25 \pm 0.02$ & $0.2 \pm 0.04$ & $3.25 \pm 0.1$ & $109 \pm 12.5$ & $98.61 \pm 0.50$ \\
\hline
\end{tabular}

FGA: Formulation of Gliclazide loaded Aerosil; FPG: Formulation of Plain Gliclazide; MP: Marketed Product. Data are expressed as mean $\pm \operatorname{SEM}(n=3) .{ }^{*} \mathrm{p}<0.05,{ }^{* *} \mathrm{p}<0.01$ and ${ }^{* *} \mathrm{p}<0.001$ versus MP- 1 . 
All the formulated tablets satisfied the compendia limits of weight variation, friability, hardness and the disintegration time (Table 3). The weight variation was within the range of $1.01 \%$ to $1.77 \%$ for each formulation, revealed that the deviation of 20 tablets of each formula was less than $7.5 \%$. The results fulfilled the pharmacopoeial limits which indicating very good uniformity in all formulations. The percentage weight loss of all formulations was varied from $0.10 \%$ to $0.38 \%$, indicating all the values are within the acceptable limits except the formulation FPG-1 and FPG-2 (1.64\% and $1.24 \%$ respectively).The hardness of the formulated tablets ranged from 2.3 to $3.35 \mathrm{~kg} / \mathrm{cm}^{2}$, where as the hardness of the marketed tablets ranged from 2.15 to $4.2 \mathrm{~kg} / \mathrm{cm}^{2}$, indicating good mechanical strength of newly formulated tablets when compared to branded products. The disintegration time (DT) of the SDs formulated tablets ranged from $21-84$ seconds, whereas the values of DT of the marketed tablets varied from 33 - 390 seconds, indicating faster release of drug when tablets are prepared using its solid dispersions.

\subsection{Dissolution Studies}

The dissolution profiles of the different tablet formulations in water medium are depicted in Table 4. The tablets prepared with plain gliclazide (FPG-1) showed $9.9 \%$ drug release in 30 minutes and $11.5 \%$ release in $60 \mathrm{~min}$, respectively. Similarly FPG-2 showed $6.8 \%$ drug release in 30 minutes and $7.7 \%$ release in $60 \mathrm{~min}$, respectively. The both formulation did not achieve $15 \%$ drug release even after 2 hr of the dissolution study. The results from these formulation exhibited very poor dissolution rate as expected due to the hydrophobic and the crystalline nature of gliclazide. Likewise, the different marketed products (MP-1, MP-2, MP-3 and MP-4) displayed very poor the dissolution profiles $(6.9 \%$ to $11 \%$ in first 30 $\min )$.

The dissolution rate in the first 30 minutes for the FGA-1, FGA-2 and FGA-3

Table 4. Dissolution pattern of different newly formulated tablets and marketed products in water medium.

\begin{tabular}{ccccccc}
\hline Formulation & $5 \mathrm{~min}$ & $15 \mathrm{~min}$ & $30 \mathrm{~min}$ & $60 \mathrm{~min}$ & $90 \mathrm{~min}$ & $120 \mathrm{~min}$ \\
\hline FGA-1 & $19.88 \pm 0.19^{* *+t \dagger}$ & $25.14 \pm 0.77^{* * *+\dagger \dagger}$ & $28.64 \pm 0.84^{* * *+\dagger \dagger}$ & $30.94 \pm 0.51^{* * *+\dagger \dagger}$ & $32.46 \pm 0.67^{* * *+\dagger \dagger}$ & $34.44 \pm 0.26^{* * *+t \dagger}$ \\
FGA-2 & $17.07 \pm 0.14^{* *+\dagger \dagger}$ & $22.37 \pm 0.59^{* * *+\dagger \dagger}$ & $24.59 \pm 0.97^{* * *+\dagger \dagger}$ & $27.47 \pm 0.57^{* * *+\dagger \dagger}$ & $29.38 \pm 0.92^{* * *+\dagger \dagger}$ & $30.79 \pm 0.59^{* * *+\dagger \dagger}$ \\
FGA-3 & $17.78 \pm 0.39^{* * *+\dagger \dagger}$ & $25.45 \pm 0.65^{* * *+\dagger \dagger}$ & $30.94 \pm 0.47^{* * *+\dagger \dagger}$ & $35.96 \pm 0.38^{* * *+\dagger \dagger}$ & $40.02 \pm 0.53^{* * *+\dagger \dagger}$ & $41.55 \pm 0.67^{* * *+\dagger \dagger}$ \\
FPG-1 & $5.80 \pm 0.31$ & $8.56 \pm 0.29$ & $9.94 \pm 0.10$ & $11.55 \pm 0.23$ & $12.65 \pm 0.86$ & $13.48 \pm 0.83$ \\
FPG-2 & $3.76 \pm 0.44$ & $5.68 \pm 0.50$ & $6.84 \pm 0.39$ & $7.71 \pm 0.36$ & $7.83 \pm 0.41$ & $8.12 \pm 0.09$ \\
MP-1 & $4.47 \pm 0.25$ & $9.49 \pm 0.23$ & $11.08 \pm 0.52$ & $12.18 \pm 0.37$ & $13.76 \pm 0.55$ & $14.08 \pm 0.45$ \\
MP-2 & $2.56 \pm 0.21$ & $4.82 \pm 0.28$ & $6.93 \pm 0.40$ & $10.11 \pm 0.45$ & $10.85 \pm 0.32$ & $12.76 \pm 0.24$ \\
MP-3 & $5.00 \pm 0.40$ & $7.83 \pm 0.34$ & $9.91 \pm 0.40$ & $10.77 \pm 0.52$ & $12.45 \pm 0.26$ & $14.06 \pm 0.44$ \\
MP-4 & $4.47 \pm 0.19$ & $5.95 \pm 0.37$ & $8.13 \pm 0.454$ & $10.19 \pm 0.50$ & $11.20 \pm 0.20$ & $12.71 \pm 0.24$ \\
\hline
\end{tabular}

FGA: Formulation of Gliclazide loaded Aerosil; FPG: Formulation of Plain Gliclazide; MP: Marketed Product. Data are expressed as mean \pm SEM $(n=3) .{ }^{*} \mathrm{p}$ $<0.05,{ }^{* *} \mathrm{p}<0.01$ and ${ }^{* * *} \mathrm{p}<0.001$ versus FPG-1. ${ }^{\dagger} \mathrm{p}<0.05,{ }^{\dagger+} \mathrm{p}<0.01$ and ${ }^{+\dagger \dagger} \mathrm{p}<0.001$ versus MP- 1 . 


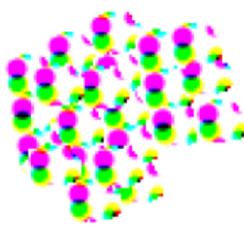

Aerosil 380
Load gliclazide

Solvent evaporation method

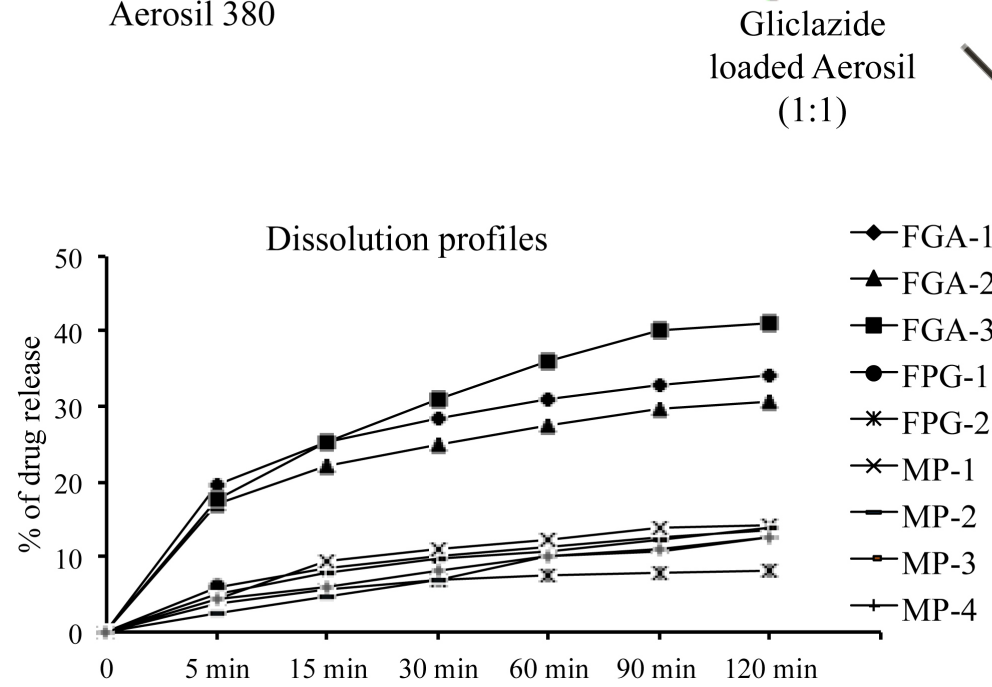

Faster Dissolution
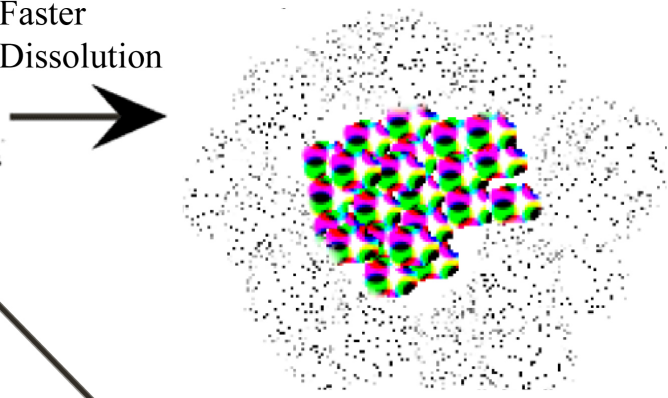

Blend with direct compressible excipients and compressed

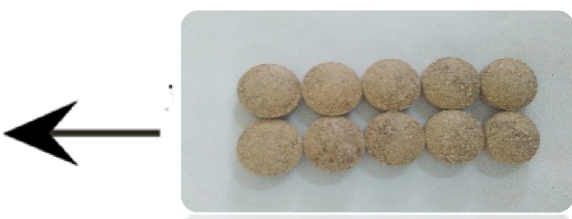

Formulated tablets met all physical parameters successfully

Figure 1. The process for SDs preparation and compressed tablets overcome the dissolution profile problems of gliclazide significantly.

formulation was observed in the range of $24.6 \%$ to $30.9 \%$, suggesting no significant effects of different diluents with different amounts on drug release from prepared tablets. Among all three formulations, FGA-3 had shown the highest drug release (35.9\%) in the $60 \mathrm{~min}$. This may be due to the presence of more hydrophilic nature cross-povidone and a high amount of the spray dried lactose that influenced to release the drug from SDs in the FGA-3 formulation.

The results of the dissolution study specify a remarkable enhancement of the dissolution rate of gliclazide in the solid dispersion formulated tablets compared to the formulated tablets containing plain gliclazide and marketed products in water medium. This is may be due to use of solid dispersion of hydrophobic drug with carriers which improves the water penetration and wettability of drug, leads to conversion of drug particles from crystalline to amorphous state, and increase the dispersibility of hydrophobic drug particles in carrier that improves the hydrophilic characteristics of drug [15] [16] [17] [18] [19].

Therefore, the process for SDs preparation and compressed tablets overcome the dissolution profile problems of gliclazide significantly (Figure 1). The data suggested the improvement of the aqueous solubility of gliclazide that could exhibit a desired absorption rate, which may in turn reflect considerable enhancement of its bioavailability and hence are more pharmacologically active.

\subsection{Stability Testing}

The formulations were subjected to disintegration time, hardness, drug assay and in vitro dissolution study after storage of three months at $40^{\circ} \mathrm{C} / 75 \% \mathrm{RH}$ and 
Table 5. Disintegration time, hardness, and drug content of FGA tablets after stability study.

\begin{tabular}{ccccccc}
\hline & \multicolumn{3}{c}{ Initial Study (Before Storage) } & \multicolumn{3}{c}{ After Three Months } \\
\cline { 2 - 7 } Formulations & $\begin{array}{c}\text { Disintegration } \\
\text { Time }(\mathrm{s})\end{array}$ & $\begin{array}{c}\text { Hardness } \\
\left(\mathrm{kg} / \mathrm{cm}^{2}\right)\end{array}$ & $\begin{array}{c}\text { Drug } \\
\text { Content }(\%)\end{array}$ & $\begin{array}{c}\text { Disintegration } \\
\text { Time }(\mathrm{s})\end{array}$ & $\begin{array}{c}\text { Hardness } \\
\left(\mathrm{kg} / \mathrm{cm}^{2}\right)\end{array}$ & $\begin{array}{c}\text { Drug } \\
\text { Content }(\%)\end{array}$ \\
\hline FGA-1 & $93.33 \pm 2.25$ & $3.16 \pm 0.12$ & $99.56 \pm 0.16$ & $78.66 \pm 2.56^{*}$ & $3.08 \pm 0.10$ & $97.31 \pm 0.43^{*}$ \\
FGA-2 & $22.33 \pm 1.89$ & $2.93 \pm 0.10$ & $99.53 \pm 0.04$ & $18.33 \pm 1.75$ & $2.91 \pm 0.05$ & $97.80 \pm 0.68$ \\
FGA-3 & $27.33 \pm 2.75$ & $3.20 \pm 0.15$ & $99.58 \pm 0.11$ & $22 \pm 2.50$ & $3.16 \pm 0.07$ & $96.77 \pm 0.052^{*}$ \\
\hline
\end{tabular}

FGA: Formulation of Gliclazide loaded Aerosil. Data are expressed as mean $\pm \operatorname{SEM}(n=3) .{ }^{*} \mathrm{p}<0.05,{ }^{* *} \mathrm{p}<$ 0.01 and ${ }^{* *} \mathrm{p}<0.001$ versus initial study.

Table 6. Dissolution profiles of FGA tablets after stability study.

\begin{tabular}{ccccccc}
\hline \multirow{2}{*}{ Time } & \multicolumn{2}{c}{ Initial Study (Before Storage) } & \multicolumn{2}{c}{ After Three Months } \\
\cline { 2 - 7 } & FGA-1 & FGA-2 & FGA-3 & FGA-1 & FGA-2 & FGA-3 \\
\hline $05 \mathrm{~min}$ & $20.07 \pm 0.35$ & $16.78 \pm 0.11$ & $16.44 \pm 0.56$ & $20.11 \pm 0.47$ & $16.49 \pm 0.18$ & $17.33 \pm 0.57$ \\
$15 \mathrm{~min}$ & $23.93 \pm 0.17$ & $21.86 \pm 0.20$ & $25.22 \pm 0.14$ & $22.50 \pm 0.24^{*}$ & $22.04 \pm 0.31$ & $23.74 \pm 0.35^{\star}$ \\
$30 \mathrm{~min}$ & $28.25 \pm 0.31$ & $24.57 \pm 0.10$ & $30.62 \pm 0.55$ & $29.21 \pm 0.46$ & $23.92 \pm 0.12^{*}$ & $29.38 \pm 0.16$ \\
$60 \mathrm{~min}$ & $31.14 \pm 0.28$ & $27.62 \pm 0.48$ & $34.53 \pm 0.56$ & $29.50 \pm 0.22^{\star}$ & $25.55 \pm 0.23^{\star}$ & $35.22 \pm 0.11$ \\
$90 \mathrm{~min}$ & $32.32 \pm 0.51$ & $28.34 \pm 0.16$ & $39.96 \pm 0.35$ & $31.46 \pm 0.21$ & $28.28 \pm 0.19$ & $39.12 \pm 0.25$ \\
$120 \mathrm{~min}$ & $33.40 \pm 0.16$ & $30.48 \pm 0.21$ & $40.37 \pm 0.11$ & $32.97 \pm 0.05$ & $29.69 \pm 0.43$ & $39.60 \pm 0.17^{\star}$ \\
\hline
\end{tabular}

FGA: Formulation of Gliclazide loaded Aerosil. Data are expressed as mean \pm SEM $(\mathrm{n}=3) .{ }^{\star} \mathrm{p}<0.05,{ }^{\star *} \mathrm{p}<$ 0.01 and ${ }^{* *} \mathrm{p}<0.001$ versus initial study.

the data showed that there was no significant change in all FGA formulation (Table 5 \& Table 6). The similarity index (F2) value of FGA-3 was found as 91.23, which is more than 50 indicating the similarity between the dissolution pattern in first 30 minutes before and after storage [20]. Further the pharmacokinetic evaluation is needed to prove the capability of Aerosil 380 solid dispersions to improve the bioavailability of gliclazide [21].

\section{Conclusion}

In the present work, an attempt has made to develop and evaluate different quality attributes of poorly water-soluble gliclazide SDs loaded with Aerosil 380 direct compressible tablet. The developed and formulated tablets fulfilled all compendial limits. The findings generated from this research indicated that solid dispersion technique with Aerosil 380 is a promising approach to enhance the dissolution rate of poorly water-soluble gliclazide tablet, which could be helped to develop better understanding and new strategies for anti-diabetic treatment. This study also suggests that poorly water-soluble drugs can play a significant role in the solid oral delivery with safe and effective alternative with low dose to the commercially available dosage forms currently used in the clinic in the near future. Furthermore, the result from this research may provide a basis for carrying further work on understanding different kind of biopharmaceutical profiles of different poorly soluble drug molecules. 


\section{Conflicts of Interest}

The authors declare no conflicts of interest regarding the publication of this paper.

\section{References}

[1] Betageri, G.V. and Makarla, K.R. (1995) Enhancement of Dissolution of Glyburide by Solid Dispersion and Lyophilization Techniques. International Journal of Pharmaceutics, 126, 155-160. https://doi.org/10.1016/0378-5173(95)04114-1

[2] Zkan, Y.O., Atay, T., Dikmen, N. and Aboul-Enein, H.Y. (2000) Improvement of Water Solubility and in Vitro Dissolution Rate of Gliclazide by Complexation with $\beta$-Cyclodextrin. Pharmaceutica Acta Helvetiae, 74, 365-370. https://doi.org/10.1016/S0031-6865(99)00063-1

[3] Alkhamis, K.A., Allaboun, H. and Al-Momani, W.Y. (2003) Study of the Solubilization of Gliclazide by Aqueous Micellar Solutions. Journal of Pharmaceutical Sciences, 92, 839-846. https://doi.org/10.1002/jps.10350

[4] Varshosaz, J., Talari, R., Mostafavi, A. and Nokhodchi, A. (2008) Dissolution Enhancement of Gliclazide Using in Situ Micronization by Solvent Change Method. Powder Technology, 187, 222-230. https://doi.org/10.1016/j.powtec.2008.02.018

[5] Saharan, V.A. and Choudhury, P.K. (2011) Dissolution Rate Enhancement of Gliclazide by Ordered Mixing. Acta Pharmaceutica, 61, 323-334.

https://doi.org/10.2478/v10007-011-0021-7

[6] Hu, J., Rogers, T.L., Brown, J., Young, T., Johnston, K.P. and Williams III, R.O. (2002) Improvement of Dissolution Rates of Poorly Water Soluble APIs Using Novel Spray Freezing into Liquid Technology. Pharmaceutical Research, 19, 1278-1284. https://doi.org/10.1023/A:1020390422785

[7] Mellaerts, R., Aerts, C.A., Van Humbeeck, J., Augustijns, P., Van den Mooter, G. and Martens, J.A. (2007) Enhanced Release of Itraconazole from Ordered Mesoporous SBA-15 Silica Materials. Chemical Communication, 13, 1375-1377. https://doi.org/10.1039/b616746b

[8] Palmer, K.J. and Brogden, R.N. (1993) Gliclazide-An Update of Its Pharmacological Properties and Therapeutic Efficacy in Non-Insulin-Dependent Diabetes-Mellitus. Drugs, 46, 92-125. https://doi.org/10.2165/00003495-199346010-00007

[9] Leuner, C. and Dressman, J. (2000) Improving Drug Solubility for Oral Delivery using Solid Dispersions. European Journal of Pharmaceutics and Biopharmaceutics, 50, 47-60. https://doi.org/10.1016/S0939-6411(00)00076-X

[10] Vasconcelos, T., Sarmento, B. and Costa, P. (2007) Solid Dispersions as Strategy to Improve Oral Bioavailability of Poor Water Soluble Drugs. Drug Discovery Today, 12, 1068-1075. https://doi.org/10.1016/j.drudis.2007.09.005

[11] Biswal, S., Sahoo, J., Murthy, P.N., Giradkar, R.P. and Avari, J.G. (2008) Enhancement of Dissolution Rate of Gliclazide Using Solid Dispersions with Polyethylene Glycol 6000. AAPS Pharmaceutical Science and Technology, 9, 563-570. https://doi.org/10.1208/s12249-008-9079-z

[12] Paul, S., Islam, M.N., Ali, M.A., Barman, R.K., Wahed, M.I.I. and Rahman, B.M. (2019) Improvement of Dissolution Rate of Gliclazide Using Solid Dispersions with Aerosil 380 and Its Effect on Alloxan Induced Diabetic Rats. Pharmacology and Pharmacy, 10, 365-385.

[13] Reddy, K.R., Mutalik, S. and Reddy, S. (2003) Once-Daily Sustained-Release Matrix Tablets of Nicorandil: Formulation and in Vitro Evaluation. AAPS Pharmaceutical 
Science and Technology, 4, 480-488. https://doi.org/10.1208/pt040461

[14] United States (2000) Pharmacopoeia 24, National Formulary 19, USP Convention. Rockville.

[15] Karavas, E., Ktissis, G., Xenakis, A. and Georgarakis, E. (2005) Miscibility Behaviour and Formation Mechanism of Stabilized Felodipine-Polyvinylpyrrolidone Amorphous Solid Dispersions. Drug Development and Industrial Pharmacy, 31, 473-489. https://doi.org/10.1080/03639040500215958

[16] Ford, J.L. (1986) The Current Status of Solid Dispersions. Pharmaceutica Acta Helvetiae, 61, 69-88.

[17] Varma, M.M. and Pandit, J.K. (2005) Dissolution, Solubility, XRD and DSC Studies on Flurbiprofen-Nicotinamide Solid Dispersions. Drug Development and Industrial Pharmacy, 31, 417-423. https://doi.org/10.1080/03639040500214613

[18] Dordunoo, S.K., Ford, J.L. and Rubinstein, M.H. (1991) Preformulation Studies on Solid Dispersions Containing Triamterene or Temazepam in Polyethylene Glycols or Gelucire 44/14 for Liquid Filling of Hard Gelatin Capsules. Drug Development and Industrial Pharmacy, 17, 1685-1713.

https://doi.org/10.3109/03639049109057315

[19] Patil, M.P. and Gaikwad, N.J. (2009) Preparation and Characterization of Gliclazide-Polyethylene Glycol 4000 Solid Dispersions. Acta Pharmaceutica, 59, 57-65.

[20] Vemula, S.K. and Bontha, V.K. (2013) Colon Targeted Gaur Gum Compression Coated Tablets of Flrbiprofen: Formlation, Development and Pharmacokinetics. BioMed Research International, 2013, Article ID: 287919.

https://doi.org/10.1155/2013/287919

[21] Bandarkar, S.F. and Ibrahim, S.K. (2011) Lyophilized Gliclazide Poloxamer, Solid Dispersions for Enhancement of in Vitro Dissolution and in Vivo Bioavailability. International Journal of Pharmacy and Pharmaceutical Sciences, 3, 122-127. 